
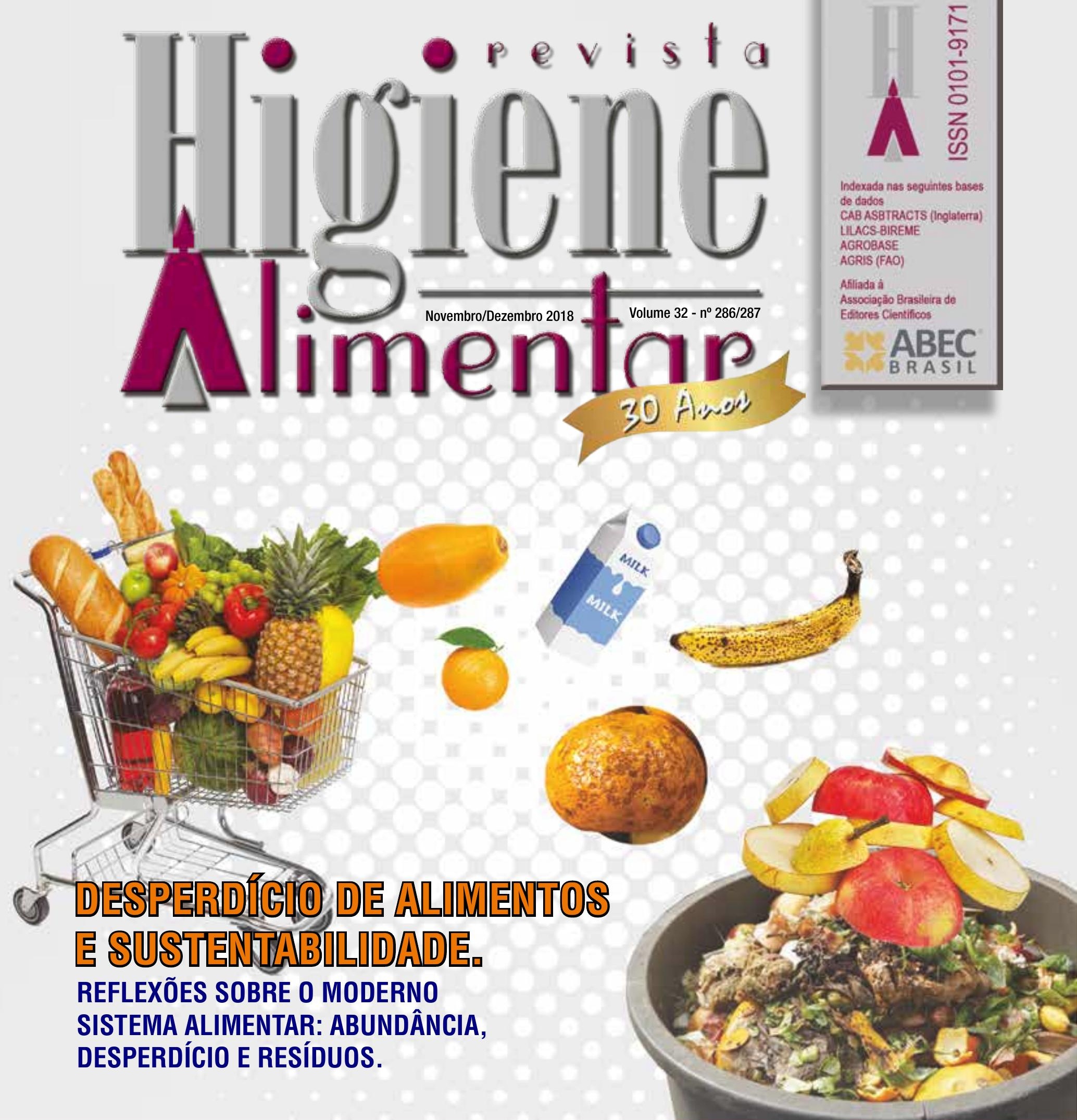

VEJA, AINDA, MAIS DUAS DEZENAS DE TRABALHOS ABSOLUTAMENTE ORIGINAIS

SURTOS DE ORIGEM ALIMENTAR NOTIFICADOS NO BRASIL DE 2015 A 2017 \&UNCIONAMENTO CLANDESTINO DE AVÍCOLAS NO MUNICÍPIO DE SÃO PAULO BARREIRAS FíSICAS NO CONTROLE DE PRAGAS E VETORES EM UAN \& EFEITO DA MATURAÇ̃̃O SECA E ÚMIDA NA QUALIDADE DA CARNE

PONTOS CRÍTICOS DE CONTRLE EM UAN HOSPITALAR \& PROCESSO COOK-CHILL NA EXTENSÃO DA VALIDADE DE ALIMENTOS

CONDIÇÕES HIGIENICOSSANITÁRIAS DE PADARIAS \& ANÁLISE MICROBIOLÓGICA DE GELO

QUALIDADE DOS ALIMENTOS COMERCIALIZADOS EM FEIRA LIVRE \& CONCENTRAÇÃO DE CLORO ATIVO EM SANITIZANTES INDUSTRIALIZADOS

ANÁLISE DE AFLATOXINAS EM PASTAS DE AMENDOIM \& PREJUÍZO ECONÔMICO POR ABSCESSOS VACINAIS EM CARCAÇAS DE BOVINOS 


\section{FLNCIONAMIENTO CLANDESTIINO}

\section{DE AVÍCOLLAS NO MIIIICÍPIO}

\section{DE SĨO PAILL.}

\author{
André Luiz Assi $\bowtie$ \\ Faculdades Metropolitanas Unidas. São Paulo, SP.
}

\section{Andréa Barbosa Boanova}

Coordenação de Vigilância em Saúde. Vigilância Sanitária de Alimentos PMSP. São Paulo, SP

Werner Souza Martins

UNESP CERe. Registro, SP

Jamila Pastori

Médica Veterinária. São Paulo, SP

\section{Simone de Carvalho Balian -}

Universidade de São Paulo. Faculdade de Medicina Veterinária e Zootecnia. Departamento de Medicina Veterinária Preventiva e Saúde Animal. São Paulo, SP

$\bowtie$ andre.assi@fmu.br

RESUMO

O Brasil possui legislação sanitária rigorosa na produção de alimentos, entretanto questões culturais frequentemente conflitam com as normas, como o abate clandestino de aves. Mesmo com toda a tecnologia empregada e rigor do sistema de inspeção brasileiro ainda verifica-se o consumo de aves provenientes desses abates. O presente estudo objetivou fazer uma análise crítica sobre a existência e funcionamento das "Avícolas" no município de São Paulo, identificar fatores facilitadores e discutir ações para mitigar os riscos sanitários dessa atividade. Utilizou-se abordagem qualitativa para análise de documentos e relatórios gerados nas rotinas de trabalho da Coordenação de Vigilância em Saúde da Prefeitura do Município de São Paulo e legislação vigente acerca do assunto. Estima-se aproximadamente 3900 estabelecimentos com condições estruturais e sanitárias irregulares, porém não há levantamentos e/ou registros. As aves não possuem procedência determinada ou

certificações sanitárias. $\mathrm{O}$ ambiente é promíscuo e insalubre, situação agravada pela falta de cuidados dos colaboradores. Há eliminação irregular de resíduos do abate, ausência de programas de autocontrole e/ou boas práticas de fabricação. Concluiu-se que as Avícolas são informais, ilegais e clandestinas, impactam negativamente a Saúde Pública pela atividade desenvolvida em desacordo com as normas sanitárias, ambientais e trabalhistas.

Palavras-Chave: Abate clandestino. Abatedouro de aves. Vigilância sanitária. Carne de frango.

\section{ABSTRACT}

Brazil has strict sanitary laws in food production. However, cultural issues often conflict with the rules, such as clandestine slaughter of birds. Even with all the technology employed and the rigor of the Brazilian inspection system, we still observe the consumption of poultry from these slaughters. This study aimed to critically analyze the existence and functioning of poultry in the city of São Paulo, to identify facilitating factors and to discuss actions to mitigate the health risks of this activity. A qualitative approach used to analyze documents and reports generated in the work routines of the Health Surveillance Coordination Office of the Municipality of São Paulo and current legislation on the subject. There are approximately 3900 establishments without structural and sanitary conditions are estimated, but there are no surveys and / or records. The birds have no specific provenance or sanitary certifications. The environment is promiscuous and unhealthy, a situation aggravated by the lack of care of employees. There is irregular disposal of slaughter residues, absence of 
self-control programs and / or good manufacturing practices. It was concluded that Poultry are informal, illegal and clandestine, negatively impact Public Health by the activity developed in disagreement with sanitary, environmental and labor standards.

Keywords: Clandestine slaughter. Poultry slaughterhouse. Health surveillance. Chicken meat.

INTRODUÇÃO

Brasil possui ampla disponibilidade de recursos naturais. Está entre os maiores produtores de alimentos no cenário mundial, sendo o maior exportador de carne de frango. A expectativa é manter o rápido crescimento na produção de carnes ao longo da próxima década, quando a carne de frango será responsável por mais da metade do crescimento projetado graças ao aumento das demandas domésticas e internacionais (OECD/FAO, 2017). Em 2050 existirão, aproximadamente, 9,6 bilhões de habitantes no mundo, sendo $66,4 \%$ deles em áreas urbanas. No Brasil, os habitantes do meio urbano passarão de $84,3 \%$ para $91 \%$ (UNITED NATIONS, 2014).

Define-se Segurança Alimentar e Nutricional - SAN como "a situação na qual toda população tem pleno acesso físico e econômico a alimentos seguros e nutritivos que satisfaçam as suas necessidades e preferências nutricionais, para levar uma vida ativa e saudável" (FAO, 2005). A produção de alimentos no Brasil precisa e deve evoluir, estabelecendo um mercado interno consistente e sólido no qual os alimentos cumpram a sua função, como direito natural do ser humano e a SAN seja um dos eixos que sustentam a Soberania Alimentar no país (MALUF; MENEZES; VALENTE, 1996). Também, é fundamental a manutenção de auditorias oficiais e supervisões técnicas de médicos veterinários garantindo a realização da inspeção ante e post mortem e uma série de outras práticas que permitam a produção de um alimento saudável e seguro para o consumidor (AMALCABURIO, 2008).

Embora o Brasil ocupe destacada posição no mercado mundial da produção e comercialização de carne de aves, ainda convive com a comercialização no mercado interno de produtos de baixa qualidade higiênica, sanitária e tecnológica em estabelecimentos conhecidos como "Avícolas".

Esses estabelecimentos, localizados em ambientes urbanos por todo o território nacional, atuam de forma irregular em relação às normas sanitárias vigentes (MENNUCCI, 2006), comercializando aves de procedência duvidosa, pequenos animais vivos e realizando o seu abate localmente desprovido de controle veterinário. Ainda, não possuem infraestrutura adequada à atividade, boas práticas de produção de alimentos, programas de qualidade e autocontrole implantados, presença do médico veterinário como responsável técnico e fiscalização do serviço de inspeção, entre outros fatores. Sua existência apoia-se na interpretação do consumidor sobre o frescor de seu produto ser superior ao produto industrializado, além de resgatar lembranças emocionais da vida no campo.

O pressuposto é de que a existência das avícolas é ilegal, suas práticas de abate e comercialização configuram alto risco de disseminação de agentes infectocontagiosos de relevância para a saúde coletiva, ambiental e das populações animais de produção. Assim, o presente estudo fez uma análise crítica sobre a existência e funcionamento das "Avícolas" na cidade de São Paulo, salientando pontos críticos de caráter sanitário relacionado ao seu funcionamento. Também, a necessidade de ações de fortalecimento do serviço de fiscalização e educação da população acerca dessa atividade e produto.

\section{MATERIAL E MÉTODOS}

Utilizou-se a metodologia estudo de caso por tratar-se de uma modalidade de pesquisa que possibilita o conhecimento de uma realidade específica. Também, de análise de documentos gerados nas rotinas de trabalho da Coordenadoria de Vigilância em Saúde da Prefeitura do Município de São Paulo - COVISA-SP no período entre janeiro e novembro do ano de 2015 e legislação vigente pertinente à temática Abate de animais de corte e inspeção sanitária de produtos de origem animal.

\section{RESULTADOS E DISCUSSÃO}

\section{Importância e Cenário das Aví- colas}

A intensificação dos processos produtivos de alimentos traz consigo o adensamento populacional de rebanhos e culturas múltiplas na mesma região, aumentando as interações intra e interespécies, criando complexos fluxos de mercadorias, pessoas e animais. Esses fenômenos facilitam a propagação de doenças, inclusive pela exposição a novos agentes zoonóticos (CUTLER; FOOKS; VAN DER POEL, 2010). A partir da regulamentação do sistema agroalimentar brasileiro determinadas atividades tradicionais passaram a uma condição de informalidade por não se adequarem às exigências mínimas para exercer a atividade. Uma delas é o abate de aves em processo não industrial. Por consequência ao longo do tempo tais setores produtivos caminham em decadência tecnológica, higiênica e sanitária, descumprindo exigências mínimas de saúde, segurança e fiscais (WILKINSON; MIOR, 1999). 
O Decreto Federal n ${ }^{\circ}$ 9.013/2017 RIISPOA define o que é abatedouro frigorífico tendo como complementos a Portaria Federal $n^{\circ} 210 / 98$, que define os requisitos necessários para abate e inspeção de carne de aves, desde a infraestrutura, tecnologias até aos procedimentos de inspeção sanitária, complementando ao Regulamento da Inspeção Industrial e Sanitária de Produtos de Origem Animal - RIISPOA, e a Instrução Normativa $n^{\circ} 56 / 2007$, definindo a necessidade de registro nos órgãos estaduais de defesa sanitária animal cumprindo os requerimentos documentais, anotação de responsabilidade técnica do médico veterinário em seu conselho estadual, assim como fiscalização por médico veterinário do serviço de inspeção correspondente ao registro.

As avícolas compreendem um modelo de comércio de aves frequente em culturas e grupos étnicos que entendem obter assim produtos de melhor frescor e características sensoriais. A epidemia de influenza iniciada no sudeste asiático em 2003 evidenciou relação direta com a venda de aves infectadas nesse tipo de estabelecimento, além de facilitar a propagação do agente infeccioso por aves selvagens (CHOMEL; BELOTTO; MESLIN, 2007). É um mercado que caminha em paralelo ao formal de abastecimento de carne de aves competindo pelo consumidor.

Alguns fatores para a permanência das Avícolas são: 1) o social, decorrente do fato de pequenos produtores criarem animais para o próprio consumo e também comercializar estes animais em suas regiões; 2) o cultural, ligado a hábitos e crenças de que as aves abatidas na hora são mais sadias e saborosas e 3) educacional (MENNUCCI, 2006). Outro fator determinante para a escolha desse produto é a memória emocional que associa a ave obtida nas avícolas, com aquela criada e abatida no quintal de casa. Uma observação pertinente adicional é o fato de que a informalidade no varejo impacta com sonegação ao fisco, além da aquisição de produtos sem inspeção sanitária (BANKUTI; SOUZA FILHO, 2006; SORIO; RASI, 2010).

Em 1991 existiam mais de 400 avícolas na cidade de São Paulo, comercializando aproximadamente 700 toneladas de carne de aves por mês (GERMANO, 1991). Em 2008, a Vigilância Sanitária do município estimava 3900 estabelecimentos dessa natureza, mas que não são números absolutos (BOANOVA; DINITZEN, 2008). Acredita-se que a carne de aves é um dos principais produtos de origem animal comercializado por via informal no município de São Paulo. São praticamente inexistentes estatísticas nacionais sobre a ocorrência das avícolas no território nacional.

Em maio de 2006 iniciou-se um trabalho no município de São Paulo pela Coordenação de Vigilância em Saúde - COVISA para coibir o abate informal (BOANOVA; DINITZEN, 2008). Entre maio de 2006 e fevereiro de 2007 realizaram-se 497 vistorias em 293 estabelecimentos de universo estimado de 3900 , sendo que $14(4,76 \%)$ encerraram suas atividades, $31(10,54 \%)$ foram advertidos e $50(17 \%)$ foram multados. Ainda, $198(67,34 \%)$ se encontravam com processos administrativos abertos até o fim desse período (BOANOVA; DINITZEN, 2008). Os imóveis onde funcionam frequentemente são adaptados, sem as mínimas condições estabelecidas pela legislação vigente para a prática do abate de aves. A origem das aves para abate e comercialização é duvidosa ou desconhecida, sendo a maioria poedeiras em situação de descarte, refugos de lotes ou mesmo aves doentes. Não possuem documentos obrigatórios, como as Guias de Trânsito Animal - GTAs (SÃO PAULO- ESTADO, 2000).
Nenhuma das avícolas vistoriadas possuía alvará para funcionar como abatedouro de pequenos animais de corte. Também não possuíam separação insuficiente das áreas de abate e alojamento das aves vivas, tampouco condições e tecnologia mínimas para realizar essa atividade, com falta de capacitação e uniforme para os trabalhadores que não possuem noções mínimas de saúde e segurança do trabalho e, portanto, desconhecem os riscos sanitários a que estão expostos durante suas práticas de trabalho. Os equipamentos, móveis e utensílios são precários, em péssimas condições de uso, higiene e segurança (NOBREGA et al., ). As aves são alojadas desrespeitando determinações quanto ao bem-estar animal, controle sanitário e normas básicas de higiene e saúde ambiental, propiciando também a propagação de zoonoses por conta do ambiente interespecífico promíscuo (SÃO PAULO- ESTADO, 1992).

\section{Riscos à Saúde Pública e à Segu- rança dos Alimentos:}

Muitas das doenças ocupacionais são zoonoses, isto é, doenças ou infecções naturalmente transmissíveis entre animais vertebrados e seres humanos (WHO - WORLD HEALTH ORGANIZATION, 2008). A rotina do trabalhador desse setor envolve uma série de riscos de infecção por agentes de doenças das aves, tais como influenza, listeriose, colibacilose, salmonelose, Doença de Newcastle, aspergilose, entre outras (FERNANDES; FURLANETO, 2004). Soma-se ao risco à saúde coletiva, a questão da poluição ambiental (SCHOENHALS, 2006).

As doenças transmitidas por alimentos - DTA são doenças causadas por bactérias, vírus, parasitas, toxinas (como as bacterianas e fúngicas), príons, agrotóxicos, produtos químicos e metais pesados presentes em alimentos ou água contaminados 
(BRASIL, 2010). Acometem, por ano, milhões de pessoas de todo o mundo (NOLLA, 2005).

No Brasil, entre 2007 e 2016 foram 6.632 surtos, 469.482 expostos, 118.104 doentes e 109 óbitos, com maior ocorrência nas regiões sudeste $(43,8 \%)$, sul $(24,8 \%)$ e centro-oeste (19,5\%). Em 66,8\% dos surtos o alimento causador não foi identificado e $70,3 \%$ não teve o micro-organismo identificado. Dentre os agente identificados $90,5 \%$ eram bactérias, se destacando Salmonella sp., Escherichia coli e Staphylococcus aureus (BRASIL, 2010). São bastante significativos o subdiagnóstico e subnotificação em nível global, o que faz com que chegue às autoridades sanitárias pequena fração de sua real ocorrência (SARAIVA et al., 2018). No estado de São Paulo, entre 2008 e 2010 foram notificados 1.831 surtos com 33.534 casos e 9 óbitos. Em 1.782 surtos foi possível identificar o local da ocorrência e, em $51,8 \%$ deles o surto aconteceu em residências (OLIVEIRA; BARATA, 2013).

Dentre os agentes infecciosos mais relevantes de serem transmitidos pela carne de aves está a Salmonella spp,, com maior risco em locais de abate clandestino, uma vez que as precárias condições físicas dos locais de abate e a falta de fiscalização da comercialização dos produtos comprometem a qualidade destes alimentos, facilitando esta contaminação (SILVA, 1999).

As condições de trabalho nesses estabelecimentos são insalubres e não atendem as exigências legais estabelecidas pelo Decreto Federal $\mathrm{n}^{\circ}$ 9.013/2017 (BRASIL, 2017). Em nenhuma das avícolas vistoriadas há um profissional responsável pelo processo, nem a atuação de inspeção veterinária, contrariando as determinações legais vigentes para o funcionamento de um abatedouro avícola.

Os recipientes são improvisados e acumulam ao final da linha de abate sujidades na água representadas por penas, fezes, sangue e partículas diversas. Não há o mínimo critério e cuidado com a higiene do local, utensílios, procedimentos e com a saúde dos trabalhadores, assim como nenhum padrão técnico implantado para manipulação e higienização das instalações. Ainda nenhum protocolo ou procedimento que busque a qualidade e segurança do produto final, tampouco do bem-estar animal.

\section{Legislação}

A comercialização da carcaça oriunda do abate clandestino é interpretada como crime contra a saúde pública (BRASIL, 1940). Neste contexto são fundamentais algumas conceituações para a melhor compreensão deste estudo: Legal - relativo à lei; conforme a lei; tudo o que não contravém a princípio de Direito, seja instituído pela lei, pelo costume ou pela jurisprudência; Ilegal - aquilo que é contrário à lei; (...) tudo que contravém ao princípio de lei em que possa exceder o seu teor; Formal relativo à lógica formal; o que se faz segundo formas predeterminadas; Informal - o que não corresponde a formas ou formalidades; Clandestino - tudo que se faz às escondidas ou ocultamento, contra norma legal instituída e com intenção dolosa ou fraude. Não é só o que se oculta. Necessário que se tenha o ânimo de burlar a lei e fraudar alguém (CUNHA, 2011) (SILVA, 2004).

O RIISPOA orienta quanto à inspeção ante mortem e post mortem dos animais, inspeção e fiscalização sob o ponto de vista industrial e sanitário em toda a produção com o objetivo de garantir a segurança e inocuidade dos alimentos. Para isso, orienta quanto à adoção de programas de autocontrole e rastreabilidade (BRASIL, 2017). Para o abate não há respeito ao tempo de jejum e técnica de insensibilização. É executado por meio de secção no pescoço da ave, sangria por decúbito em um cone de metal, sem controle de tempo de escoamento do sangue, assim como não há controle do binômio tempo $X$ temperatura na escaldagem, em desacordo à Instrução Normativa $n^{\circ}$ 210/1998 do Ministério da Agricultura, Pecuária e Abastecimento MAPA (BRASIL, 1998).

De acordo com todo o exposto pode-se afirmar que as Avícolas são: Informais, pois não agem/funcionam dentro das normas predeterminadas; Ilegais, pois são contra diversas legislações do nível municipal ao nacional, de diversas naturezas, como ambientais, trabalhistas, fiscais e sanitárias, e; Clandestinas, pois não possuem cadastro nos órgãos reguladores competentes, como a vigilância sanitária, serviço de inspeção, tampouco alvará de funcionamento. $\mathrm{O}$ problema inicia na questão cultural da população, sendo pertinentes ações educativas acerca do assunto.

Caracterizando-se de tal forma como um mercado ilegal, as Avícolas corroboram para um grave problema de saúde pública. Sendo na maior cidade brasileira quanto a população e economia exige uma atuação efetiva e permanente para impedir o funcionamento desses estabelecimentos por conta do alto risco epidemiológico que representam. Para isso, são essenciais ações integradas dos poderes executivo, legislativo e judiciário para maior eficiência e agilidade em garantir a saúde pública. Também, há a necessidade de revisão do sistema de fiscalização, visando celeridade e eficiência, além de suporte e recursos para as equipes responsáveis. Ainda, que leis pertinentes à saúde pública não sejam aprovadas sem possuir parecer técnico de órgãos diretamente envolvidos, de forma a proteger a população de interesses políticos em detrimento à saúde pública. 


\section{CONCLUSÃO}

O presente artigo concluiu que as avícolas são estabelecimentos informais, ilegais e clandestinos, além de ser questão de extrema importância para a saúde pública. As carcaças expostas à comercialização representam risco para à saúde pública por serem oriundas de aves sem procedência e frequentemente procedentes do descarte de granjas industriais.

A questão não se restringe somente à prática do abate clandestino. Inicia-se no sistema de obtenção destas aves e fragilidade do sistema de fiscalização como um todo por falta de recursos e interesse em resolver o problema, aumentando o risco de proliferação de doenças zoonóticas e a possibilidade de oferecer a carne de um animal enfermo para consumo. As Avícolas impactam negativamente a Saúde Pública em questões sanitárias, ambientais e trabalhistas; não cumprem exigências legais mínimas relativas ao bem-estar animal; e ferem a legislação fiscal, visto que não há recolhimento de tributos. Também não existe gestão de resíduos, sendo mais um fator de preocupação para o saneamento básico. Faz-se também necessárias ações educativas à população acerca do assunto, além de prover investimento e suporte aos serviços de fiscalização e melhorias no sistema judiciário buscando celeridade. Leis sobre saúde pública devem possuir parecer técnico de órgãos diretamente envolvidos como forma de proteger a população.

REFERÊNCIAS

AMALCABURIO, R. Homeopatia em frangos de corte criados em sistema de semi-confinamento alternativo. 2008. Universidade Federal de Santa Catarina, 2008.

BANKUTI, FI; SOUZA FILHO, HM. S. A informalidade em sistemas agroindustriais: os casos dos sistemas agroindustriais da carne bovina e do leite. In: ZUIN, LFS; QUEIROZ, TR (Ed.). Agronegócios: gestão e inovação. São Paulo: Saraiva, 2006. p. $58-90$.

BOANOVA, AB; DINITZEN, CB. Programa de Proibição de Abate de Aves Sem Inspeção em Avícolas do Município de São Paulo. Rev. Higiene Alimentar, v. 21, n. 150, p. 367-368, 2008.

BRASIL. PORTARIA NN 210 DE 10 DE NOVEMBRO DE 1998 do Ministério da Agricultura, Pecuária e Abastecimento - Regulamento Técnico da Inspeção Tecnológica e Higiênico Sanitária de Carnes de Aves. Brasilia, Brasil. DOU, 1998. .

BRASIL. Manual integrado de prevenção e controle de doenças transmitidas por alimentos do ministério da saúde. Secretaria de Vigilância em Saúde, 2010. .

BRASIL. Decreto № 9.013, de 29 de março de 2017. Regulamenta a Lei $n^{\circ}$ 1.283, de 18 de dezembro de 1950, e a Lei $n^{0} 7.889$, de 23 de novembro de 1989, que dispõem sobre a inspeção industrial e sanitária de produtos de origem animal. Brasilia, Brasil. DOU, 2017. Disponível em: <http://www2. camara.leg.br/legin/fed/decret/2017/ decreto-9013-29-marco-2017-784536-normaatualizada-pe.doc>.

CHOMEL, BB; BELOTTO, A; MESLIN, FX. Wildlife, Exotic Pets, and Emerging Zoonoses. Emerging Infectious Diseases, v. 13, n. 1, p. 6-11, 2007. Disponível em: <https://www.ncbi.nlm. nih.gov/pmc/articles/PMC2725831/>.

CUNHA, S. S. da. Dicionário Compacto do Direito. $11^{\mathrm{a}}$ ed. São Paulo: Saraiva, 2011.

CUTLER, SJ; FOOKS, AR; VAN DER POEL, WHM. Public Health Threat of New, Reemerging, and Neglected Zoonoses in the Industrialized World. Emerging Infectious Diseases, v. 16, n. 1, p. 1-7, 2010. Disponível em: <http://wwwnc.cdc.gov/eid/ article/16/1/08-1467_intro.htm>.

FAO. Conferência regional FAO / OMS sobre Segurança Alimentar para África - Análise da situação dos sistemas de segurança sanitária dos alimentos em Angola. Harare, Zimbabwe, 2005.

FERNANDES, FC.; FURLANETO, A. Riscos Biológicos em Aviários. Rev Bras Medicina do Trabalho, v. 2, n. 049, p. 140-152, 2004.

GERMANO, P. Comércio Clandestino de Produtos Animais Prejudica Saúde Pública. Rev Higiene Alimentar, v. 5, n. 18, p. 11-12, 1991.

MALUF, RS; MENEZES, F; VALENTE, FL. Contribuição ao Tema da Segurança Alimentar no Brasil. Rev Cadernos de Debate, v. IV, p. 66-88, 1996.

MENNUCCI, TA. Abate clandestino de aves em avícolas. 2006. Universidade Castelo Branco, 2006.

NOBREGA, EL et al. Estudo das Condições Higiênico Sanitárias das Avícolas no Município de São Paulo. [s.d.]

NOLLA, AC. Relação entre a ocorrência de enteroparasitoses em manipuladores de alimentos e aspectos epidemiológicos em Florianópolis, Santa Catarina , Brasil Relationship between intestinal parasites in food handlers and epidemiological factors in the city of Flori. Cad. Saúde Pública, v. 21, n. 2, p. 641-645, 2005.

OECD/FAO. OECD-FAO Agricultural Outlook 2017-2026. [s.l: s.n.]

OLIVEIRA, MEB; BARATA, RCB. Surtos de Doenças Transmitidas por Alimentos no Estado de São Paulo, 2008-2010BEPA. Boletim Epidemiológico Paulista (Online). [s.l: s.n.].

SÃO PAULO (ESTADO). LEI ESTADUAL No 7.705 DE 19 DE FEVEREIRO DE 1992 - Normas para abate de animais destinados ao consumo. São Paulo, BrasilSecretaria de Estado do Governo e Gestão Estratégica, , 1992. 24 DE OUTUBRO DE 2000 - Dispõe 
sobre a adoção de medidas de defesa sanitária animal no âmbito do Estado e dá outras providências correlatas.São Paulo, Brasil, 2000. . Disponivel em: <http://www.comitepcj.sp.gov.br/download/Lei_10670_ Defesa_Animal.pdf>.

SARAIVA, M. et al. Investigação laboratorial de surtos de toxinfeção alimentar, 2016. Boletim Epidemiológico Observações, v. 7, n. 21, p. 24-28, 2018.

SCHOENHALS, M. Avaliação da eficiência do processo de flotação aplicado ao tratamento primário de efluentes de abatedouro avícola, v. 3, n. 1989, p. 5-24, 2006.

SILVA, DPE. Vocabulário Jurídico. 25a ed. Rio de Janeiro: Companhia Editora Forense, 2004.

SILVA, J. A. As novas perspectivas para 0 controle sanitário dos alimentos. Rev Hgiene Alimentar, v. 13, n. 65 , p. 19-25, 1999.

SORIO, A.; RASI, L. Ovinocultura e abate clandestino: um problema fiscal ou uma solução de mercado? Rev Política Agrícola, n. 1, p. 71-83, 2010.
UNITED NATIONS. World Population Prospects: The 2014 Revision.

WHO - WORLD HEALTH ORGANIZATION. Zoonoses and veterinary public health (VPH). Disponivel em: <http:// www.who.int/zoonoses/en/>. Acesso em: 20 nov. 2015.

WILKINSON, J.; MIOR, L. Setor informal, produção familiar e pequena agroindústria: interfaces. Estudos Sociedade e Agricultura, v. 13, p. 29-45, 1999. Disponível em: <http://r1.ufrrj. br/esa/V2/ojs/index.php/esa/article/ view/159>.

\section{ANUÁRIO SOBRE CONTROLE DE ALIMENTOS DE ORIGEM ANIMAL.}

0 Ministério da Agricultura, Pecuária e Abastecimento (MAPA) publicou a quarta edição do Anuário dos Programas de Controle de Alimentos de Origem Animal - 2018. Os dados, apresentados pelo Departamento de Inspeção de Produtos de Origem Animal, trazem os resultados das 25.007 análises do Programa de Avaliação de Conformidade de Produtos de Origem Animal realizadas em 2017.

0 índice de conformidade das 2.961 amostras analisadas de produtos de origem animal, coletadas nos estabelecimentos registrados no Sistema de Inspeção Federal (SIF), foi de $85,61 \%$, representando evolução sobre a conformidade de $83,85 \%$ de 2016. Nas análises microbiológicas foi atingida conformidade em $91,30 \%$ das amostras. Esses controles estão previstos no Programa Nacional de Controle de Patógenos (PNCP) que visa monitorar a presença de Listeria monocytogenes em produtos de origem animal prontos para consumo, Escherichia coli produtora de Shiga toxina (STEC) e Salmonella spp. em carne de bovinos e carcaças de frangos e perus.

Em 324 amostras também foram realizadas análises para pesquisar indícios de fraude. Nas amostras de leite, foi pesquisada a adição de soro, açúcares, sais, conservantes, dentre outras substâncias proibidas, através do levantamento ou quantificação dos parâmetros de amido, cloretos, neutralizantes da acidez e sacarose, entre outros. Verificou-se que o índice de conformidade do leite pasteurizado foi de $89,39 \%$, do leite UHT foi de $93,91 \%$, e do leite em pó foi de $97,53 \%$.

Nas carcaças de frango, foi apurado se havia adição de água e o índice de conformidade foi de 76,69\%. No pescado, o índice de conformidade para análise de desglaciamento (eliminação da fina camada de gelo existente no pescado congelado, que serve como proteção ao produto) foi de $86,67 \%$.

Assim como nos anos anteriores, não foram contemplados os estabelecimentos localizados em Santa Catarina, filiados ao Sindicato dos Armadores e das Indústrias da Pesca de Itajaí e Região (SINDIPI), por haver determinação judicial, sendo que esta região está entre as principais do setor de indústrias de pesca do país.

0 anuário apresenta ainda os resultados das análises de ações de combate à fraude, do Plano Nacional de Controle de Resíduos e Contaminantes (PNCRC/Animal) e do Regime de Alerta de Importação (RAl).

Em 2017, após a deflagração pela Polícia Federal da Operação Carne Fraca, o Ministério coletou 762 amostras junto aos 21 frigoríficos citados pela PF, para avaliar a segurança sanitária de produtos cárneos fabricados por esses estabelecimentos. Do total de 762 amostras analisadas, $683(89,63 \%)$ não apresentaram nenhuma irregularidade quanto aos parâmetros físico-químicos e microbiológicos. Em 69 amostras (9,05\%), foram detectados problemas de ordem econômica como, por exemplo, excesso de amido em salsicha, adição de água além do permitido em frango, uso do conservante ácido sórbico em produtos em que este não é permitido. Somente em 10 amostras (1,31\%) foram detectados problemas microbiológicos como presença de Salmonella, Staphylococcus coagulase positiva e coliformes. (Ministério da Agricultura,dez 2018) 